\title{
The role of diffusion tensor imaging in the diagnosis, prognosis, and assessment of recovery and treatment of spinal cord injury: a systematic review
}

\author{
Orel A. Zaninovich, MD, ${ }^{1}$ Mauricio J. Avila, MD, MHPE, ${ }^{2}$ Matthew Kay, MBBS, ${ }^{3}$ \\ Jennifer L. Becker, BMBS, MRCS, FRCR, ${ }^{3}$ R. John Hurlbert, MD, PhD, ${ }^{2}$ and \\ Nikolay L. Martirosyan, MD, $\mathrm{PhD}^{2}$ \\ ${ }^{1}$ College of Medicine, ${ }^{2}$ Division of Neurosurgery, ${ }^{3}$ Department of Medical Imaging, University of Arizona, Tucson, Arizona
}

\begin{abstract}
OBJECTIVE Diffusion tensor imaging (DTI) is an MRI tool that provides an objective, noninvasive, in vivo assessment of spinal cord injury $(\mathrm{SCl})$. DTI is significantly better at visualizing microstructures than standard MRI sequences. In this imaging modality, the direction and amplitude of the diffusion of water molecules inside tissues is measured, and this diffusion can be measured using a variety of parameters. As a result, the potential clinical application of DTI has been studied in several spinal cord pathologies, including SCl. The aim of this study was to describe the current state of the potential clinical utility of DTI in patients with $\mathrm{SCl}$ and the challenges to its use as a tool in clinical practice.
\end{abstract}

METHODS A search in the PubMed database was conducted for articles relating to the use of DTI in SCl. The citations of relevant articles were also searched for additional articles.

RESULTS Among the most common DTI metrics are fractional anisotropy, mean diffusivity, axial diffusivity, and radial diffusivity. Changes in these metrics reflect changes in tissue integrity. Several DTI metrics and combinations thereof have demonstrated significant correlations with clinical function both in model species and in humans. Its applications encompass the full spectrum of the clinical assessment of $\mathrm{SCl}$ including diagnosis, prognosis, recovery, and efficacy of treatments in both the spinal cord and potentially the brain.

CONCLUSIONS DTI and its metrics have great potential to become a powerful clinical tool in SCl. However, the current limitations of DTI preclude its use beyond research and into clinical practice. Further studies are needed to significantly improve and resolve these limitations as well as to determine reliable time-specific changes in multiple DTI metrics for this tool to be used accurately and reliably in the clinical setting.

https://thejns.org/doi/abs/10.3171/2019.1.FOCUS18591

KEYWORDS diffusion tensor imaging; spinal cord injury; fractional anisotropy; MRI; magnetic resonance imaging

$\mathrm{S}$ PINAL cord injury (SCI) is a prevalent problem affecting 17,700 new people every year in the US. ${ }^{44}$ It is estimated that approximately 288,000 people live with an SCI in the US. It is important to have quantifiable modalities in SCI to provide support for clinical decision making. One of those objective modalities is MRI, and more specifically diffusion tensor imaging (DTI) in patients with SCI (Figs. 1 and 2).

DTI was first described by Basser et al. in 1994 in a study demonstrating that this imaging modality was significantly better at visualizing microstructures than other
MR sequences, namely T1- and T2-weighted images (Fig. 3). ${ }^{4,34}$ DTI measures the direction of diffusion of water molecules inside tissues. In the axon, water diffusion is mostly limited by the cell membrane and myelin sheath barriers; this leads to a gradient with high diffusion in the direction parallel to the white matter tracts and low diffusion perpendicular to the white matter tracts. ${ }^{13,20,58}$ Disruption of the biological barriers is thought to result in increased radial diffusivity (RD) by providing an alternate, perpendicular path for water diffusion. ${ }^{48,50,53}$

Diffusion is measured in different ways in DTI: the

ABBREVIATIONS $A D=$ axial diffusivity; $A D C=$ apparent diffusion coefficient; $A S I A=$ American Spinal Injury Association; BASIC $=$ Brain and Spinal Injury Center; $D T I=$ diffusion tensor imaging; $\mathrm{FA}=$ fractional anisotropy; $\mathrm{MD}=$ mean diffusivity; $\mathrm{RD}=$ radial diffusivity; $\mathrm{SCl}=$ spinal cord injury.

SUBMITTED October 30, 2018. ACCEPTED January 7, 2019

INCLUDE WHEN CITING DOI: 10.3171/2019.1.FOCUS18591. 
two most frequently used measurements are fractional anisotropy (FA), the extent to which diffusion is limited to specific directions, and mean diffusivity (MD), the overall amount of diffusion in a sample or voxel (Fig. 4). ${ }^{7} \mathrm{FA}$ is a measure of microstructural integrity because it is sensitive to microstructural changes in the spinal cord, but it is not specific to underlying pathological causes. ${ }^{1}$ In contrast, MD is a measure of membrane density and is more sensitive for changes in cellularity, edema, and necrosis.

The purpose of this review was to describe the current state of DTI as a potential clinical tool for the assessment and management of SCI. We aimed to summarize the most up-to-date advances in DTI and its potential utility in diagnosis, prognosis, assessment of recovery, and of therapeutic interventions.

\section{Methods}

This review was prepared using the Preferred Reporting Items for Systematic Reviews and Meta-Analyses (PRISMA) statement. ${ }^{42}$

\section{Search Criteria}

The MEDLINE database (via PubMed) was searched for articles published between January 2000 and April 2017 with the following search terms: "diffusion tensor imaging" AND "spinal cord injury". The search was narrowed by selecting the "human" link for species and limiting the results. After reviewing title and abstract, the articles were then included in the final review. The citations from the preselected articles were then screened for additional relevant articles (Fig. 5).

\section{Inclusion Criteria}

Articles that contained information relevant to the use of DTI in SCI were included. Articles that discussed the limitations precluding the use of DTI in SCI were also included.

\section{Data Evaluation}

Relevant results from individual articles were extracted and organized into the clinically relevant categories of diagnosis, prognosis, recovery, assessment of therapeutic interventions, and limitations.

\section{Results}

Our search resulted in 306 publications that were narrowed to 33 articles based on the inclusion criteria. The remaining 41 papers were found by searching the citations of identified articles (Fig. 5).

\section{Utility of DTI as a Diagnostic Tool for SCI}

DTI can identify the location and severity of injury to the spinal cord, and is therefore an important tool for diagnosis of SCI. ${ }^{15,27}$ Postprocessing MR software is available to quantify DTI metrics at specified spinal levels and can also be used to allow the data to be displayed in a visual format that allows easier interpretation (Fig. 6). Several metrics in DTI have been studied in SCI, including FA,

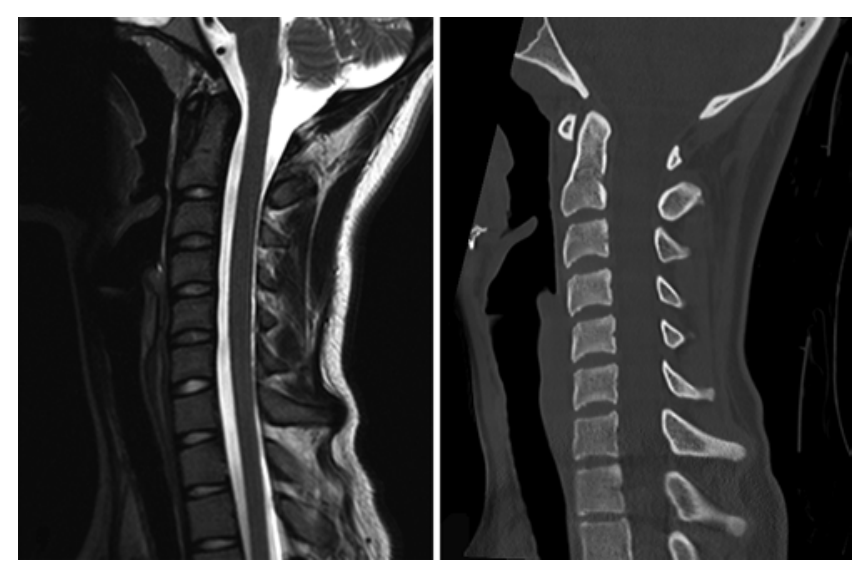

FIG. 1. Representative sagittal T2-weighted MR image (left) acquired at $3 \mathrm{~T}$ and sagittal CT image (right) (Siemens Healthineers) of a normal cervical spine with normal osseous alignment, no fracture or abnormal marrow signal, and no abnormal cord signal to indicate an $\mathrm{SCl}$.
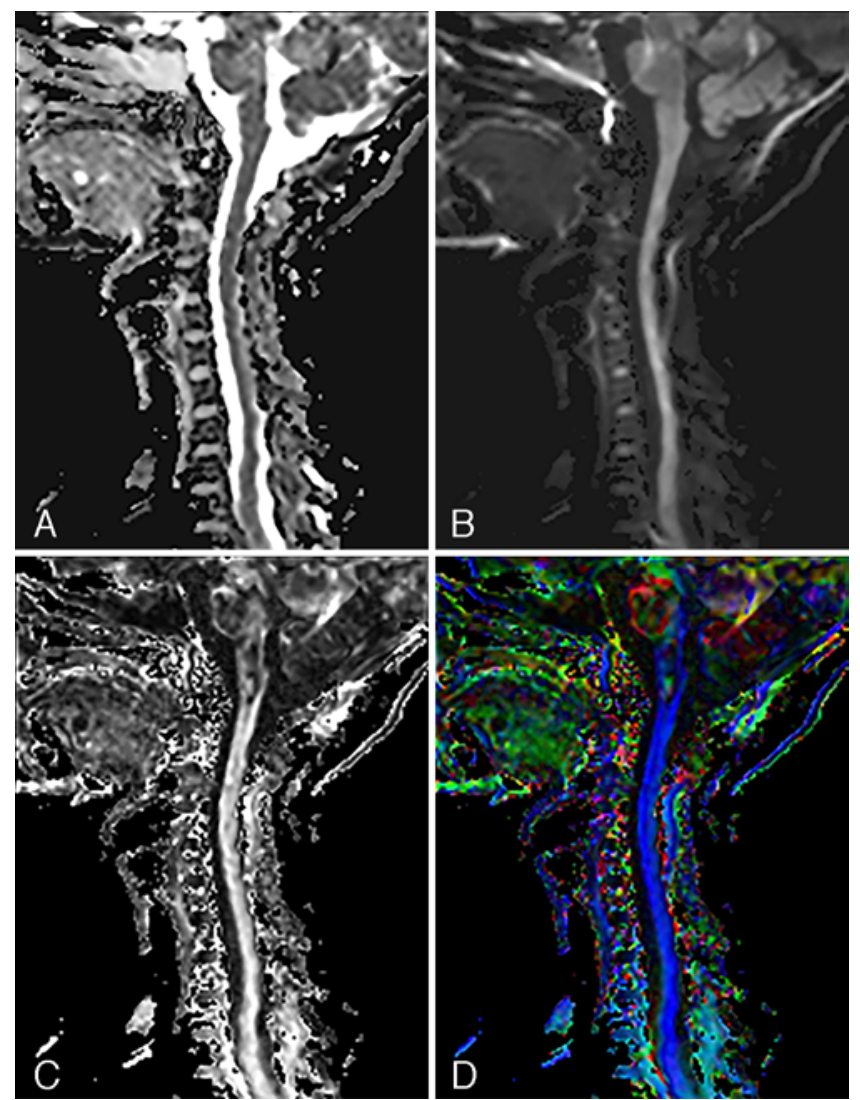

FIG. 2. Representative sagittal ADC (A), diffusion-weighted (B), FA (C), and reformatted color FA (D) MR images acquired at 3 T of the cervical spine in Fig. 1 with uniform cord signal throughout each of the sequenc$\mathrm{es}$, which is consistent with absence of an $\mathrm{SCl}$. The FA sequence is a gray-scale map of DTI FA values, with brightness corresponding to more anisotropy. The reformatted color FA sequence assigns colors that are based on anisotropy and direction from the FA data. 

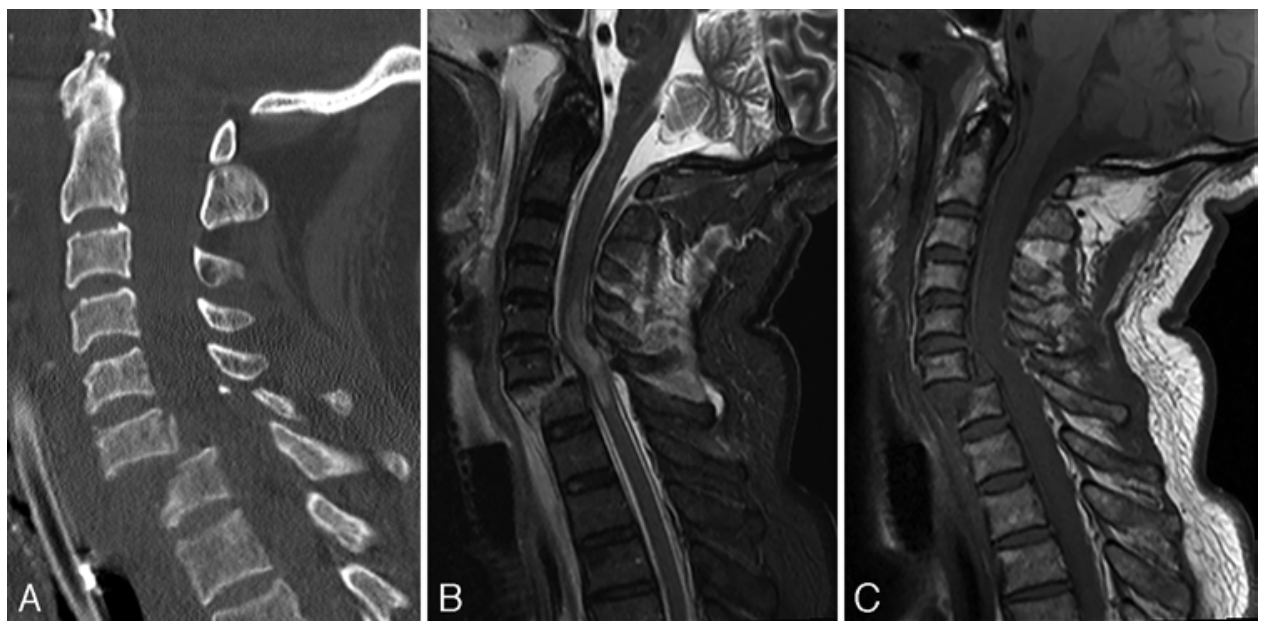

FIG. 3. Representative sagittal CT (A), sagittal STIR (B), and T1 (C) MR images at 3 T of an ASIA grade A SCI in the setting of a 3-column injury with traumatic anterolisthesis of $\mathrm{C} 6$ on $\mathrm{C} 7$ due to an acute $\mathrm{C} 6 / \mathrm{C} 7$ intervertebral disc injury, significant ligamentous injuries (anterior longitudinal ligament, posterior longitudinal ligament, and ligamentum flavum tears), fracture of the $\mathrm{C} 7$ anterosuperior endplate, multiple posterior element fractures (not all shown), and the associated cervical cord injury extending from $\mathrm{C} 4$ to C7/T1.

MD, radial anisotropy, RD, and apparent diffusion coefficient (ADC) values.

\section{FA Values}

The mean FA value has been consistently found to be reduced in both human and animal studies of individuals with SCI compared to healthy controls. 2,6,8,10-12,14-16,28,32-35, $40,41,43,45,47,51,55,59,65,68,71,74$ With respect to the level of spinal injury, D'souza et al. found that the mean FA values in cervical spine injury were significantly reduced compared to healthy controls at the level of injury but not at levels above or below the injury. ${ }^{15}$ FA levels have been shown to decrease with increasing canal stenosis, and several studies have shown a correlation between FA value reduction and severity of SCI. ${ }^{33,46}$

Asymmetrical FA values between left and right corticospinal tracts were found to moderately correlate with laterality of neurological symptoms and American Spinal Injury Association (ASIA) scores using tract-specific DTI (Fig. 7). ${ }^{38}$

\section{Values}

Most commonly, MD values increase following acute SCI. ${ }^{10,14,15,40,65}$ D'souza et al. found a statistically significant increase in MD values post-SCI at the injured spinal level, but not at the level above or below the injury. ${ }^{15}$ They also found an inverse linear relationship between MD scores at the level of injury and clinical SCI assessment; the highest MD values represented worse clinical grades Additionally, MD values have been found to change with age, further confounding the interpretation of results. ${ }^{64}$

\section{ADC Values}

ADC is a measure of the magnitude of water molecule diffusion inside a tissue, and changes in this value represent a change in the tissue structure. The ADC values in SCI vary substantially by study. In their animal study,
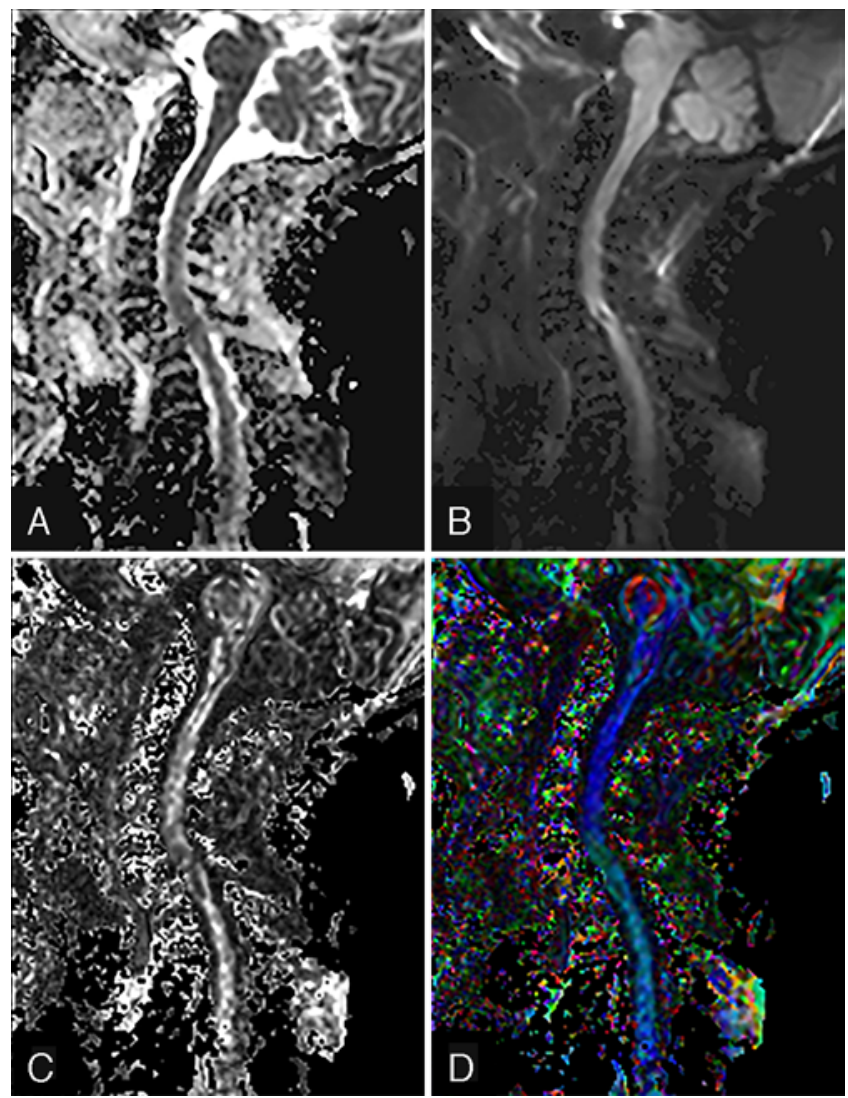

FIG. 4. Representative sagittal ADC (A), diffusion-weighted (B), FA (C), and reformatted color FA (D) MR images acquired at 3 T of the ASIA grade A SCl in Fig. 3 with signal loss centrally within the cord at $\mathrm{C} 6$ / C7 due to cord hemorrhage-related susceptibility artifact and loss of anisotropy below $\mathrm{C} 4 / \mathrm{C} 5$ on the FA-dependent sequences ( $\mathrm{C}$ and $\mathrm{D}$ ). The FA sequence is a gray-scale map of DTI FA values with brightness corresponding to more anisotropy. The reformatted color FA sequence assigns colors that are based on anisotropy and direction from the FA data. 


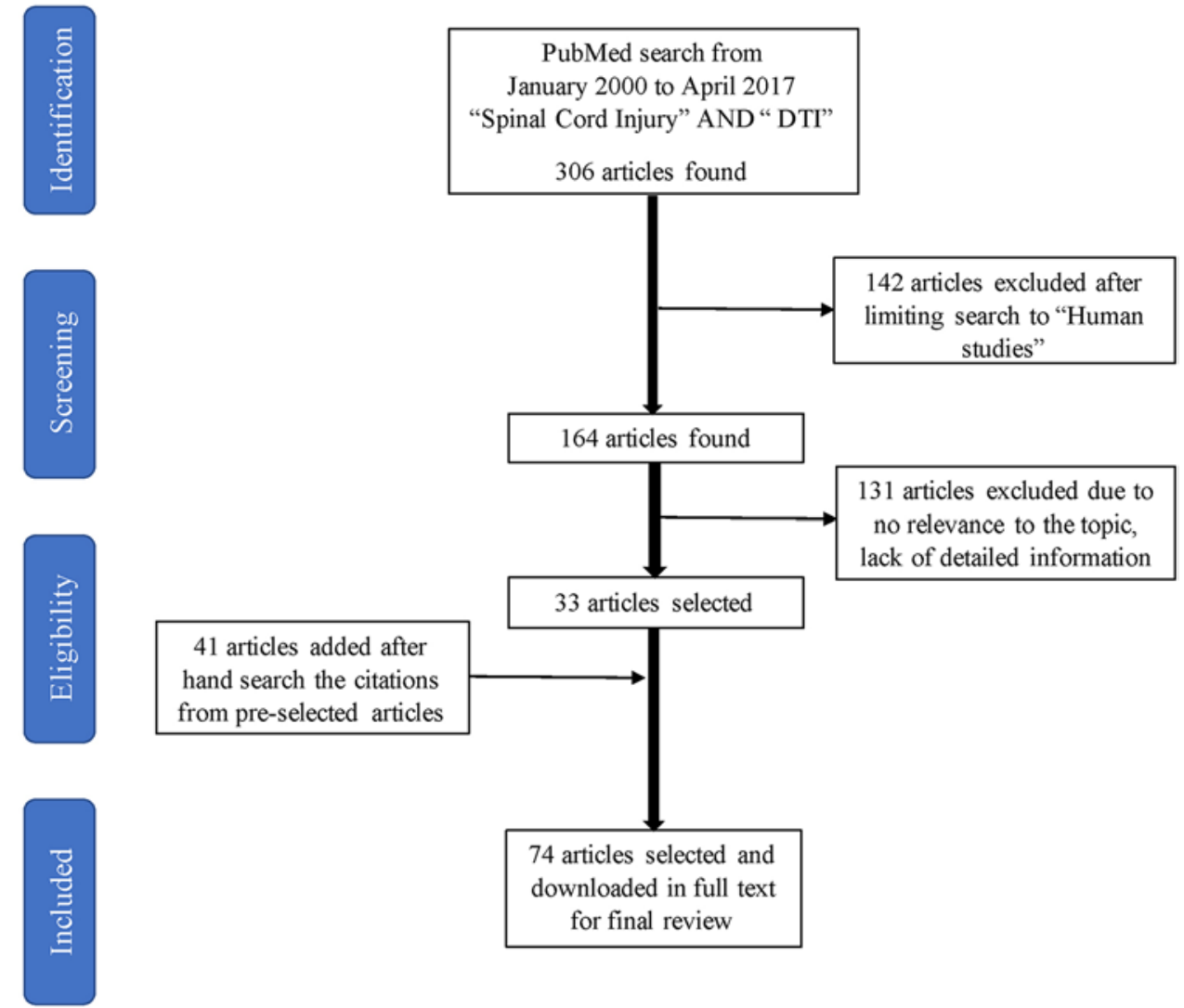

FIG. 5. Flow diagram of the search criteria used and the results from the MEDLINE database (via PubMed).

Ellingson et al. found a decreased ADC value at 2 weeks after SCI in the cord rostral and caudal to the site of injury, whereas ADC values were only slightly decreased at the level of injury. ${ }^{16}$ In their cohort of patients with SCI, Shanmuganathan et al. also found significantly decreased ADC values in the cervical spine; however, this study found decreases at levels above, below, and at the site of injury. ${ }^{51}$ In contrast, Song et al. found elevated ADC values in SCI patients relative to controls and Petersen et al. found no significant change in ADC values after SCI. ${ }^{47,55}$ Importantly, Li et al. found that ADC values in mild SCI were elevated compared to healthy controls whereas they were decreased in moderate and severe SCI. ${ }^{35}$

\section{$A D$ and $R D$ Values}

Axial diffusivity (AD) is usually high in spinal cord DTI due to axon and myelin integrity that inhibits water diffusion across the membrane, whereas AD decreases with axonal injury. 1,29,52,54 In contrast, RD increases with increased demyelination and axonal injury.,52,54,58 Although AD and RD values are a useful metric in DTI, they remain too inconsistent on their own to be used exclusively as a reliable method of diagnosing SCI.

\section{Utility of Cortical DTI for SCI}

There is evidence that DTI of cortical and brainstem structures demonstrates chronic changes after SCI and may contribute to assessing the severity and prognosis of, as well as recovery from, SCI. ${ }^{26,49,57,70}$ Sun et al. demonstrated significantly reduced FA and increased AD and RD values in both the cerebral peduncles and internal capsule in patients with cervical spine ASIA grade A/B SCI.57 Differences were also noted in cervical spine ASIA grade $\mathrm{D}$ and thoracic SCI, but were not statistically significant.

\section{Utility as a Prognostic Tool}

Postinjury neurological functional outcome is highly correlated with axonal injury as determined by histological analysis..$^{21,39}$ DTI metrics correlate with histological axonal injury as well as functional recovery. ${ }^{17,18,30,31,46,72,73}$ Ellingson et al. found that the combination of DTI fiber tract density, FA values, and MD values were the best predictor of motor impairment in the modified Japanese Orthopaedic Association scores in cervical spondylosis. ${ }^{18}$ In their study, at the site of spinal cord compression, higher fiber tract density, lower FA, and higher MD were associated with worse neurological function. Similar results were found with maximum tract density and modified Japanese Orthopaedic Association scores. ${ }^{19}$

\section{Utility in Assessment of Therapeutic Interventions}

$\mathrm{Gu}$ et al. described an experiment in which rats underwent laminectomy with spinal cord contusion and subsequent injection of olfactory ensheathing cells. DTI was used to demonstrate SCI as well as axonal regeneration at 

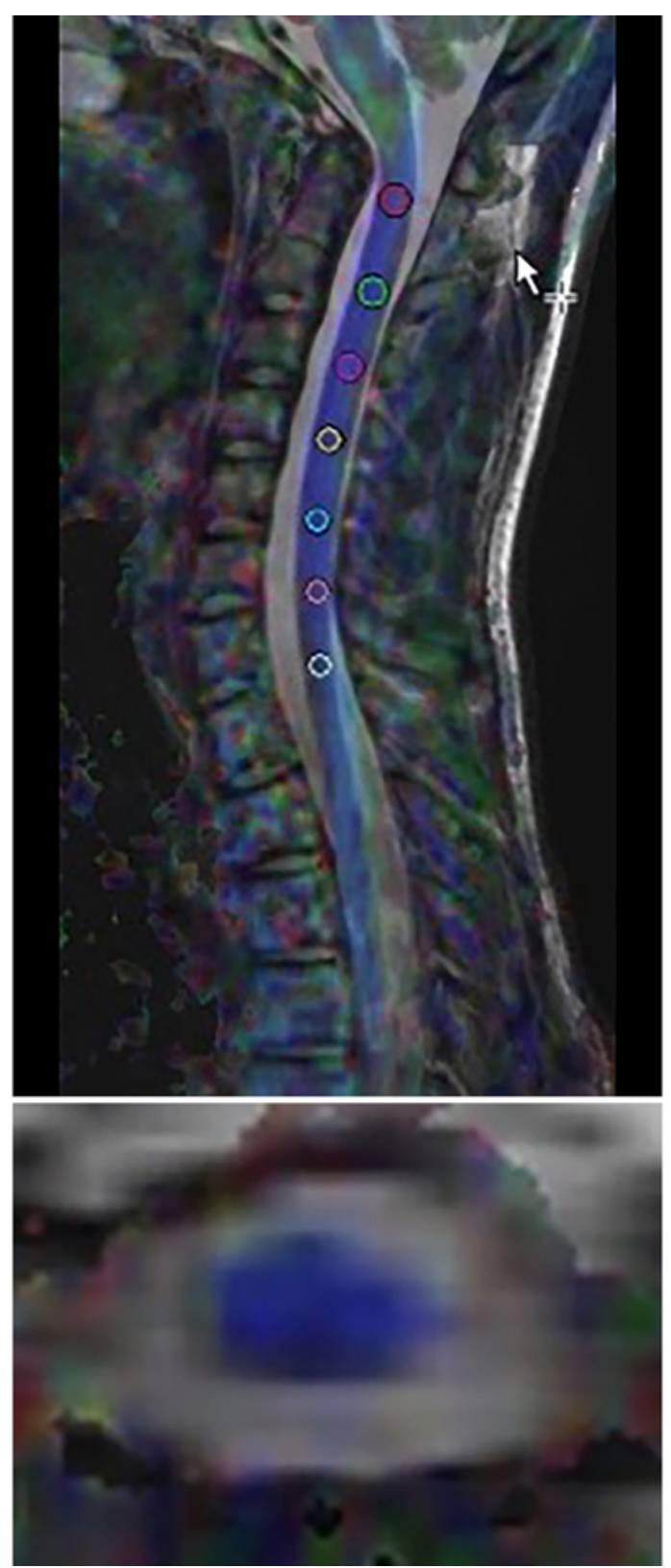

FIG. 6. An example of sagittal (upper) and axial (lower) images that fuse the colored FA map onto a T2-weighted MR image by using postprocessing software (SyngoVia VB30A; Siemens Healthineers) so that regions of interest can be selected and quantitative data can be acquired.

the injury epicenter, which was corroborated by histopathology.22 The study demonstrated increases in FA values and improved Basso-Beattie-Bresnahan scores with time.

In their animal model of SCI, Jirjis et al. used DTI to assess changes in histopathology and functional metrics at the cervical cord after injury, and compared these to changes in DTI after neuronal stem cell transplantation into thoracic spinal cord. ${ }^{25} \mathrm{FA}$, longitudinal diffusion, RD, and MD values increased in cervical segments in the stem cell-transplanted groups relative to controls. However, there was no significant change in functional recovery as

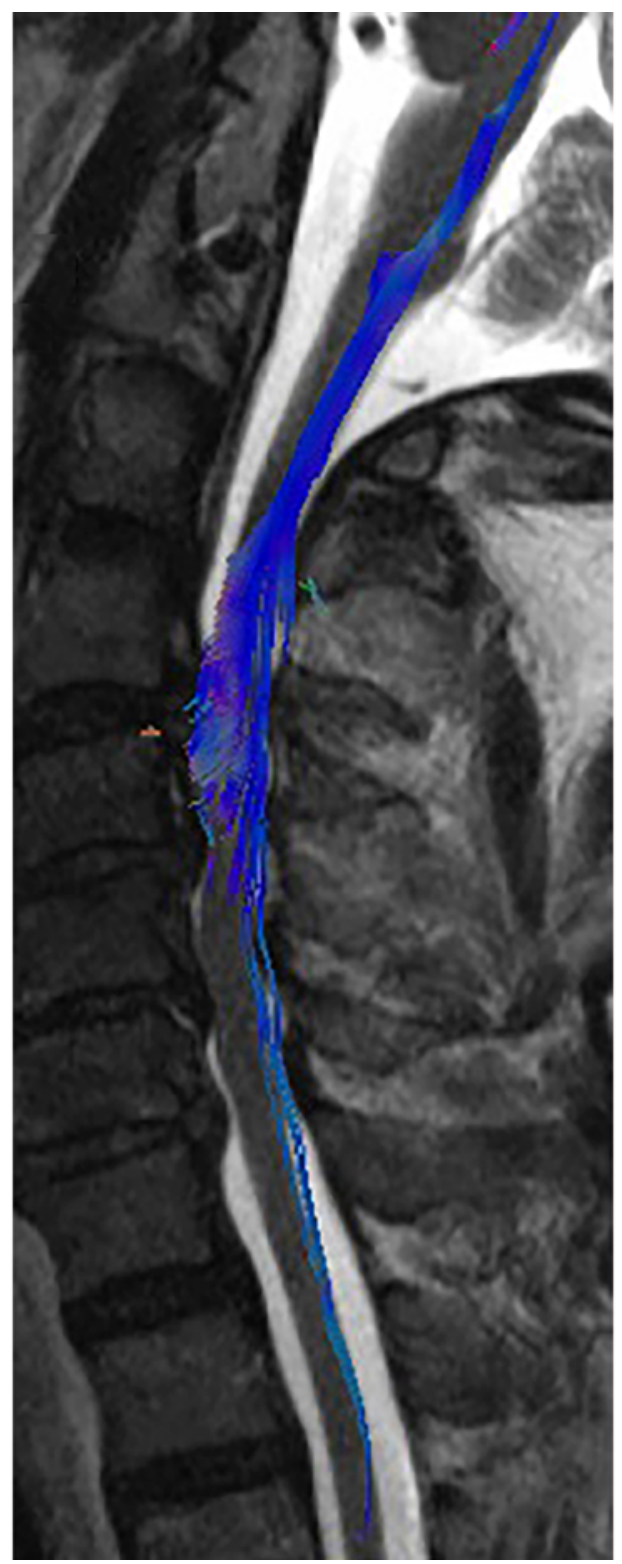

FIG. 7. An example of a sagittal fiber tracking map that is fused onto a T2-weighted MR image by using postprocessing software. The image demonstrates significant disruption of the fiber tracts in the setting of an ASIA grade A SCl.

assessed by Basso-Beattie-Bresnahan scores, suggesting that changes in DTI metrics may demonstrate changes in white matter recovery but may not always correlate to clinical improvement. Similar results were found by Bazley et al., who found increases in FA that correlated with improvements in cell survival and somatosensory evoked potentials after treatment of SCI with oligodendrocyte precursor cell transplantation. ${ }^{6}$

\section{Other MRI Modalities for SCI Assessment}

The Brain and Spinal Injury Center (BASIC) scoring system was developed to evaluate T2-weighted MR images in patients with SCI. ${ }^{60}$ The BASIC grading system is 
based on axial T2-weighted images. The BASIC scale has 5 points-from 0 (no cord signal abnormalities) to 4 (intramedullary T2 hyperintensity with microhemorrhage). The authors of this study found good correlation with a high BASIC grade and a worse clinical SCI (higher ASIA grade). A limitation of the scale is the high variance of T2 signal in images obtained $>24$ hours after injury. ${ }^{36,56,60}$ Nonetheless, the BASIC system would be easier to implement because $\mathrm{T} 2$ sequences are obtained routinely for patients with SCI. ${ }^{60}$

\section{Limitations of DTI Utility in SCI}

Inconsistencies in the changes in DTI metrics among studies preclude this imaging modality from consistent and reliable clinical use. A potentially interesting solution to this problem is the use of machine learning via a training data set of injured and healthy patients that could serve to establish different metrics to improve diagnostic accuracy of DTI. ${ }^{61}$

The specificity and sensitivity of DTI decreases with increasingly complex tissue. ${ }^{63}$ SCI results in several pathologies that are difficult to distinguish on DTI, including inflammation, edema, demyelination, and hemorrhage. 9,57 , $59,66,67$

$\mathrm{Li}$ et al. found that changes in ADC and FA values could be detected on 3.0-T machines, but changes in ADC values were not detected by a General Electric 1.5-T machine and changes in FA values were not detected by a Philips 1.5-T machine. ${ }^{34}$ A 3.0-T machine may be required for the reliable measurements of DTI metrics necessary for clinical use.

DT image quality can be significantly reduced and result in artificial alteration of DTI metrics due to patient and physiological motion., ${ }^{7,40,62}$ Methods to improve motion correction have been developed with promising results., $23,24,37,40,69$

\section{Conclusions}

DTI has great potential to provide an objective, in vivo clinical assessment of SCI. Several DTI metrics, and combinations thereof, have demonstrated significant correlations with clinical function in both animal models and humans. The applications of this tool encompass the spectrum of clinical and functional assessment in SCI including diagnosis, prognosis, recovery, and efficacy of treatments in both the spinal cord and potentially the brain. However, DTI carries several limitations that have prevented its transition beyond research into clinical practice. Further studies are needed to significantly improve and resolve these limitations as well as create standard, time-specific changes in DTI metrics that will be required for accurate and reliable use of DTI in the clinical setting. This review is limited by the absence of randomized controlled human trials and reliance on data from animal and class II-IV human studies.

\section{Acknowledgments}

Except for Fig. 5, all figures are research images that we obtained using Siemens Healthineers MR and/or CT scanners, and Figs. 6 and 7 were also processed using Siemens Healthineers postprocessing software (SyngoVia VB30A).

\section{References}

1. Alexander AL, Hurley SA, Samsonov AA, Adluru N, Hosseinbor AP, Mossahebi P, et al: Characterization of cerebral white matter properties using quantitative magnetic resonance imaging stains. Brain Connect 1:423-446, 2011

2. Alizadeh M, Intintolo A, Middleton DM, Conklin CJ, Faro SH, Mulcahey MJ, et al: Reduced FOV diffusion tensor MR imaging and fiber tractography of pediatric cervical spinal cord injury. Spinal Cord 55:314-320, 2017

3. Bammer R, Fazekas F, Augustin M, Simbrunner J, StrasserFuchs S, Seifert T, et al: Diffusion-weighted MR imaging of the spinal cord. AJNR Am J Neuroradiol 21:587-591, 2000

4. Basser PJ, Mattiello J, LeBihan D: MR diffusion tensor spectroscopy and imaging. Biophys J 66:259-267, 1994

5. Basser PJ, Pierpaoli C: A simplified method to measure the diffusion tensor from seven MR images. Magn Reson Med 39:928-934, 1998

6. Bazley FA, Pourmorteza A, Gupta S, Pashai N, Kerr C, All AH: DTI for assessing axonal integrity after contusive spinal cord injury and transplantation of oligodendrocyte progenitor cells, in 2012 Annual International Conference of the IEEE Engineering in Medicine and Biology Society. New York: IEEE, 2012, Vol 2012, pp 82-85

7. Bosma R, Stroman PW: Diffusion tensor imaging in the human spinal cord: development, limitations, and clinical applications. Crit Rev Biomed Eng 40:1-20, 2012

8. Cheran S, Shanmuganathan K, Zhuo J, Mirvis SE, Aarabi B, Alexander MT, et al: Correlation of MR diffusion tensor imaging parameters with ASIA motor scores in hemorrhagic and nonhemorrhagic acute spinal cord injury. J Neurotrauma 28:1881-1892, 2011

9. Chiang CW, Wang Y, Sun P, Lin TH, Trinkaus K, Cross AH, et al: Quantifying white matter tract diffusion parameters in the presence of increased extra-fiber cellularity and vasogenic edema. Neuroimage 101:310-319, 2014

10. Choe AS, Belegu V, Yoshida S, Joel S, Sadowsky CL, Smith $\mathrm{SA}$, et al: Extensive neurological recovery from a complete spinal cord injury: a case report and hypothesis on the role of cortical plasticity. Front Hum Neurosci 7:290, 2013

11. Cohen-Adad J, Buchbinder B, Oaklander AL: Cervical spinal cord injection of epidural corticosteroids: comprehensive longitudinal study including multiparametric magnetic resonance imaging. Pain 153:2292-2299, 2012

12. Cohen-Adad J, Leblond H, Delivet-Mongrain H, Martinez M, Benali H, Rossignol S: Wallerian degeneration after spinal cord lesions in cats detected with diffusion tensor imaging. Neuroimage 57:1068-1076, 2011

13. DeBoy CA, Zhang J, Dike S, Shats I, Jones M, Reich DS, et al: High resolution diffusion tensor imaging of axonal damage in focal inflammatory and demyelinating lesions in rat spinal cord. Brain 130:2199-2210, 2007

14. Deo AA, Grill RJ, Hasan KM, Narayana PA: In vivo serial diffusion tensor imaging of experimental spinal cord injury. J Neurosci Res 83:801-810, 2006

15. D'souza MM, Choudhary A, Poonia M, Kumar P, Khushu S: Diffusion tensor MR imaging in spinal cord injury. Injury 48:880-884, 2017

16. Ellingson BM, Kurpad SN, Schmit BD: Ex vivo diffusion tensor imaging and quantitative tractography of the rat spinal cord during long-term recovery from moderate spinal contusion. J Magn Reson Imaging 28:1068-1079, 2008

17. Ellingson BM, Kurpad SN, Schmit BD: Functional correlates of diffusion tensor imaging in spinal cord injury. Biomed Sci Instrum 44:28-33, 2008

18. Ellingson BM, Salamon N, Hardy AJ, Holly LT: Prediction of neurological impairment in cervical spondylotic myelopathy using a combination of diffusion MRI and proton MR spectroscopy. PLoS One 10:e0139451, 2015

19. Ellingson BM, Salamon N, Woodworth DC, Holly LT: Cor- 
relation between degree of subvoxel spinal cord compression measured with super-resolution tract density imaging and neurological impairment in cervical spondylotic myelopathy. J Neurosurg Spine 22:631-638, 2015

20. Feldman HM, Yeatman JD, Lee ES, Barde LHF, GamanBean S: Diffusion tensor imaging: a review for pediatric researchers and clinicians. J Dev Behav Pediatr 31:346-356, 2010

21. Ferguson AR, Irvine KA, Gensel JC, Nielson JL, Lin A, Ly J, et al: Derivation of multivariate syndromic outcome metrics for consistent testing across multiple models of cervical spinal cord injury in rats. PLoS One 8:e59712, 2013

22. Gu M, Gao Z, Li X, Guo L, Lu T, Li Y, et al: Conditioned medium of olfactory ensheathing cells promotes the functional recovery and axonal regeneration after contusive spinal cord injury. Brain Res 1654 (Pt A):43-54, 2017

23. Gudbjartsson H, Maier SE, Jolesz FA: Double line scan diffusion imaging. Magn Reson Med 38:101-109, 1997

24. Holder CA, Muthupillai R, Mukundan S Jr, Eastwood JD, Hudgins PA: Diffusion-weighted MR imaging of the normal human spinal cord in vivo. AJNR Am J Neuroradiol 21:1799-1806, 2000

25. Jirjis MB, Valdez C, Vedantam A, Schmit BD, Kurpad SN: Diffusion tensor imaging as a biomarker for assessing neuronal stem cell treatments affecting areas distal to the site of spinal cord injury. J Neurosurg Spine 26:243-251, 2017

26. Jirjis MB, Vedantam A, Budde MD, Kalinosky B, Kurpad SN, Schmit BD: Severity of spinal cord injury influences diffusion tensor imaging of the brain. J Magn Reson Imaging 43:63-74, 2016

27. Jones JGA, Cen SY, Lebel RM, Hsieh PC, Law M: Diffusion tensor imaging correlates with the clinical assessment of disease severity in cervical spondylotic myelopathy and predicts outcome following surgery. AJNR Am J Neuroradiol 34:471-478, 2013

28. Kelley BJ, Harel NY, Kim CY, Papademetris X, Coman D, Wang X, et al: Diffusion tensor imaging as a predictor of locomotor function after experimental spinal cord injury and recovery. J Neurotrauma 31:1362-1373, 2014

29. Kim JH, Budde MD, Liang HF, Klein RS, Russell JH, Cross $\mathrm{AH}$, et al: Detecting axon damage in spinal cord from a mouse model of multiple sclerosis. Neurobiol Dis 21:626632,2006

30. Kim JH, Loy DN, Wang Q, Budde MD, Schmidt RE, Trinkaus K, et al: Diffusion tensor imaging at 3 hours after traumatic spinal cord injury predicts long-term locomotor recovery. J Neurotrauma 27:587-598, 2010

31. Koskinen E, Brander A, Hakulinen U, Luoto T, Helminen $\mathrm{M}$, Ylinen A, et al: Assessing the state of chronic spinal cord injury using diffusion tensor imaging. J Neurotrauma 30:1587-1595, 2013

32. Lee JW, Kim JH, Park JB, Park KW, Yeom JS, Lee GY, et al: Diffusion tensor imaging and fiber tractography in cervical compressive myelopathy: preliminary results. Skeletal Radiol 40:1543-1551, 2011

33. Lee S, Lee YH, Chung TS, Jeong EK, Kim S, Yoo YH, et al: Accuracy of diffusion tensor imaging for diagnosing cervical spondylotic myelopathy in patients showing spinal cord compression. Korean J Radiol 16:1303-1312, 2015

34. Li XF, Yang Y, Lin CB, Xie FR, Liang WG: Assessment of the diagnostic value of diffusion tensor imaging in patients with spinal cord compression: a meta-analysis. Braz J Med Biol Res 49:e4769, 2016

35. Li XH, Li JB, He XJ, Wang F, Huang SL, Bai ZL: Timing of diffusion tensor imaging in the acute spinal cord injury of rats. Sci Rep 5:12639, 2015

36. Machino M, Yukawa Y, Ito K, Nakashima H, Kanbara S, Morita D, et al: Can magnetic resonance imaging reflect the prognosis in patients of cervical spinal cord injury without radiographic abnormality? Spine (Phila Pa 1976) 36:E1568E1572, 2011

37. Maier SE, Gudbjartsson H, Patz S, Hsu L, Lovblad KO, Edelman RR, et al: Line scan diffusion imaging: characterization in healthy subjects and stroke patients. AJR Am J Roentgenol 171:85-93, 1998

38. Maki S, Koda M, Saito J, Takahashi S, Inada T, Kamiya K, et al: Tract-specific diffusion tensor imaging reveals laterality of neurological symptoms in patients with cervical compression myelopathy. World Neurosurg 96:184-190, 2016

39. Medana IM, Esiri MM: Axonal damage: a key predictor of outcome in human CNS diseases. Brain 126:515-530, 2003

40. Middleton DM, Mohamed FB, Barakat N, Hunter LN, Shellikeri S, Finsterbusch J, et al: An investigation of motion correction algorithms for pediatric spinal cord DTI in healthy subjects and patients with spinal cord injury. Magn Reson Imaging 32:433-439, 2014

41. Mohamed FB, Hunter LN, Barakat N, Liu CSJ, Sair H, Samdani AF, et al: Diffusion tensor imaging of the pediatric spinal cord at 1.5T: preliminary results. AJNR Am J Neuroradiol 32:339-345, 2011

42. Moher D, Liberati A, Tetzlaff J, Altman DG, Antes G, Barbour $\mathrm{V}$, et al: Preferred reporting items for systematic reviews and meta-analyses: The PRISMA statement (Chinese edition). J Chin Integr Med 7:889-896, 2009

43. Mulcahey MJ, Samdani AF, Gaughan JP, Barakat N, Faro S, Shah P, et al: Diagnostic accuracy of diffusion tensor imaging for pediatric cervical spinal cord injury. Spinal Cord 51:532-537, 2013

44. National Spinal Cord Injury Statistical Center: The 2015 Annual Statistical Report. Birmingham, AL: NSCISC, 2015 (https://www.nscisc.uab.edu/PublicDocuments/ reports/pdf/2015\%20NSCISC\%20Annual\%20Statistical\%20 Report\%20Complete\%20Public\%20Version.pdf) [Accessed January 10, 2019]

45. Oakden W, Kwiecien JM, O'Reilly MA, Dabrowski W, Whyne C, Finkelstein J, et al: Quantitative MRI in a nonsurgical model of cervical spinal cord injury. NMR Biomed 28:925-936, 2015

46. Patel SP, Smith TD, VanRooyen JL, Powell D, Cox DH, Sullivan PG, et al: Serial diffusion tensor imaging in vivo predicts long-term functional recovery and histopathology in rats following different severities of spinal cord injury. $\mathbf{J}$ Neurotrauma 33:917-928, 2016

47. Petersen JA, Wilm BJ, von Meyenburg J, Schubert M, Seifert B, Najafi Y, et al: Chronic cervical spinal cord injury: DTI correlates with clinical and electrophysiological measures. J Neurotrauma 29:1556-1566, 2012

48. Rajasekaran S, Kanna RM, Shetty AP: Diffusion tensor imaging of the spinal cord and its clinical applications. J Bone Joint Surg Br 94:1024-1031, 2012

49. Ramu J, Herrera J, Grill R, Bockhorst T, Narayana P: Brain fiber tract plasticity in experimental spinal cord injury: diffusion tensor imaging. Exp Neurol 212:100-107, 2008

50. Ries M, Jones RA, Dousset V, Moonen CT: Diffusion tensor MRI of the spinal cord. Magn Reson Med 44:884-892, 2000

51. Shanmuganathan K, Gullapalli RP, Zhuo J, Mirvis SE: Diffusion tensor MR imaging in cervical spine trauma. AJNR Am J Neuroradiol 29:655-659, 2008

52. Song SK, Sun SW, Ju WK, Lin SJ, Cross AH, Neufeld AH: Diffusion tensor imaging detects and differentiates axon and myelin degeneration in mouse optic nerve after retinal ischemia. Neuroimage 20:1714-1722, 2003

53. Song SK, Sun SW, Ramsbottom MJ, Chang C, Russell J, Cross AH: Dysmyelination revealed through MRI as increased radial (but unchanged axial) diffusion of water. Neuroimage 17:1429-1436, 2002

54. Song SK, Yoshino J, Le TQ, Lin SJ, Sun SW, Cross AH, et 
al: Demyelination increases radial diffusivity in corpus callosum of mouse brain. Neuroimage 26:132-140, 2005

55. Song T, Chen WJ, Yang B, Zhao HP, Huang JW, Cai MJ, et al: Diffusion tensor imaging in the cervical spinal cord. Eur Spine J 20:422-428, 2011

56. Sun LQ, Shen Y, Li YM: Quantitative magnetic resonance imaging analysis correlates with surgical outcome of cervical spinal cord injury without radiologic evidence of trauma. Spinal Cord 52:541-546, 2014

57. Sun P, Murphy RKJ, Gamble P, George A, Song SK, Ray WZ: Diffusion assessment of cortical changes, induced by traumatic spinal cord injury. Brain Sci 7:21, 2017

58. Sun SW, Liang HF, Trinkaus K, Cross AH, Armstrong RC, Song SK: Noninvasive detection of cuprizone induced axonal damage and demyelination in the mouse corpus callosum. Magn Reson Med 55:302-308, 2006

59. Sundberg LM, Herrera JJ, Narayana PA: In vivo longitudinal MRI and behavioral studies in experimental spinal cord injury. J Neurotrauma 27:1753-1767, 2010

60. Talbott JF, Whetstone WD, Readdy WJ, Ferguson AR, Bresnahan JC, Saigal R, et al: The Brain and Spinal Injury Center score: a novel, simple, and reproducible method for assessing the severity of acute cervical spinal cord injury with axial T2-weighted MRI findings. J Neurosurg Spine 23:495-504, 2015

61. Tay B, Hyun JK, Oh S: A machine learning approach for specification of spinal cord injuries using fractional anisotropy values obtained from diffusion tensor images. Comput Math Methods Med 2014:276589, 2014

62. Tu TW, Budde MD, Xie M, Chen YJ, Wang Q, Quirk JD, et al: Phase-aligned multiple spin-echo averaging: a simple way to improve signal-to-noise ratio of in vivo mouse spinal cord diffusion tensor image. Magn Reson Imaging 32:13351343,2014

63. Tu TW, Frank JA: Assessing white matter integrity in experimental spinal cord injury using diffusion tensor imaging. $\mathbf{J}$ Neurosci Neuroeng 2:415-430, 2013

64. Uda T, Takami T, Sakamoto S, Tsuyuguchi N, Yamagata T, Ohata K: Normal variation of diffusion tensor parameters of the spinal cord in healthy subjects at 3.0-Tesla. J Craniovertebr Junction Spine 2:77-81, 2011

65. Wang KY, Idowu O, Thompson CB, Orman G, Myers C, Riley LH III, et al: Tract-specific diffusion tensor imaging in cervical spondylotic myelopathy before and after decompressive spinal surgery: preliminary results. Clin Neuroradiol 27:61-69, 2017

66. Wang X, Cusick MF, Wang Y, Sun P, Libbey JE, Trinkaus K, et al: Diffusion basis spectrum imaging detects and distinguishes coexisting subclinical inflammation, demyelination and axonal injury in experimental autoimmune encephalomyelitis mice. NMR Biomed 27:843-852, 2014

67. Wang Y, Wang Q, Haldar JP, Yeh FC, Xie M, Sun P, et al:
Quantification of increased cellularity during inflammatory demyelination. Brain 134:3590-3601, 2011

68. Wei CW, Tharmakulasingam J, Crawley A, Kideckel DM, Mikulis DJ, Bradbury CL, et al: Use of diffusion-tensor imaging in traumatic spinal cord injury to identify concomitant traumatic brain injury. Arch Phys Med Rehabil 89 (12 Suppl):S85-S91, 2008

69. Welsh CL, DiBella EVR, Hsu EW: Higher-order motioncompensation for in vivo cardiac diffusion tensor imaging in rats. IEEE Trans Med Imaging 34:1843-1853, 2015

70. Wrigley PJ, Gustin SM, Macey PM, Nash PG, Gandevia SC, Macefield VG, et al: Anatomical changes in human motor cortex and motor pathways following complete thoracic spinal cord injury. Cereb Cortex 19:224-232, 2009

71. Yoo WK, Kim TH, Hai DM, Sundaram S, Yang YM, Park MS, et al: Correlation of magnetic resonance diffusion tensor imaging and clinical findings of cervical myelopathy. Spine $\mathbf{J}$ 13:867-876, 2013

72. Yoon H, Kim J, Moon WJ, Nahm SS, Zhao J, Kim HM, et al: Characterization of chronic axonal degeneration using diffusion tensor imaging in canine spinal cord injury: a quantitative analysis of diffusion tensor imaging parameters according to histopathological differences. J Neurotrauma 34:3041-3050, 2017

73. Zhang J, Jones M, DeBoy CA, Reich DS, Farrell JAD, Hoffman PN, et al: Diffusion tensor magnetic resonance imaging of Wallerian degeneration in rat spinal cord after dorsal root axotomy. J Neurosci 29:3160-3171, 2009

74. Zhao C, Rao JS, Pei XJ, Lei JF, Wang ZJ, Yang ZY, et al: Longitudinal study on diffusion tensor imaging and diffusion tensor tractography following spinal cord contusion injury in rats. Neuroradiology 58:607-614, 2016

\section{Disclosures}

Dr. Becker has a research contract with Siemens Healthineers.

\section{Author Contributions}

Conception and design: Martirosyan. Acquisition of data: Martirosyan, Zaninovich, Avila. Analysis and interpretation of data: Martirosyan, Zaninovich, Avila. Drafting the article: Zaninovich, Avila. Critically revising the article: Martirosyan, Kay, Becker, Hurlbert. Reviewed submitted version of manuscript: all authors. Approved the final version of the manuscript on behalf of all authors: Martirosyan. Administrative/technical/material support: Martirosyan, Hurlbert. Study supervision: Becker, Hurlbert.

\section{Correspondence}

Nikolay L. Martirosyan: University of Arizona, Tucson, AZ. nmartirosyan@email.arizona.edu. 